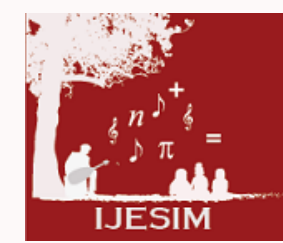

International Journal of Educational Studies in Mathematics

\title{
Reflections from a Learning Setting Designed to Investigate Mathematical Thinking
}

\author{
Derya Çelik ${ }^{1}$, Mustafa Güler², Buket Özüm Bülbül ${ }^{3}$, Zeynep Medine Özmen ${ }^{3}$ \\ ${ }^{1}$ Karadeniz Technical University, Fatih Faculty of Education, Department of Elementary Mathematics Education, Trabzon, TURKEY \\ ${ }^{2}$ Karadeniz Technical University, Institute of Education Sciences, Department of Elementary Mathematics Education, Trabzon, TURKEY \\ ${ }^{3}$ Karadeniz Technical University, Institute of Education Sciences, Department of Secondary Mathematics Education, Trabzon, TURKEY
}

\section{ABSTRACT}

In this study, it is aimed to describe mathematical thinking of teacher candidates in an adidactic learning setting. To be able to reach this aim, five stages of an adidactic learning setting were considered which were presented by Brousseau (2002) in a problem statement. The research was conducted with 30 students who were studying at second grade of primary mathematics education program at a state university, 2012-2013 academic year. As data collective tool; video records of learning setting, field notes of researchers and papers involve explanations of participants pertain to problem. During activity, participants were handed out pens and paper so as to record their thinking process completely. At the end of the study it was observed that adidactic learning setting supported participants and researchers to uncover their mathematical thinking process. Besides, observations of the researcher indicated that active participations of the students were high level during the conducted instruction. From the results of this study it was concluded that this type of activities are important at the point of informing pre-service teachers about the adidactic settings which has an important potential of provoking mathematical thinking.

Keywords:

adidactic learning setting, mathematical thinking, problem solving

(c) 2015 IJESIM. All rights reserved

Article History:

Received 08.01.2015 Received in revised form 24.02.2015 Accepted 11.09.2015 Available online 20.10.2015

\section{Extended Abstract}

\section{Introduction}

When the curriculums are examined all around the world, it can be seen that one of the aims of the mathematics education is to raise individuals who have strong power of thinking. As a matter of fact, the NCTM (2000) pointed out that the necessity of mathematical thinking as a need for mathematics education. When the mathematics curriculum in Turkey which is renewed in 2013 is investigated, it is pointed out that compare to the previous generation today's world that we come across new problems and as society we are in great need of individuals whose mathematical power of thinking is strong, who value mathematics, use mathematics for modelling and solving problems more than anytime (MEB, 2013). When it is taken into consideration that mathematics is a habit of thinking itself (Costa \& Kallick, 2000a), mathematical thinking is a topic that we need to pay more attention.

Many studies aimed to analyze the mathematical thinking emphasize the importance of problem solving. Problem solving is also considered a milestone by many education theories. Didactical learning theory came up towards the end of 20th century which deals with not teaching action, but the action how

\footnotetext{
${ }^{1}$ Corresponding author's address: Department of Elementary Education, Fatih Faculty of Education, Karadeniz Technical University, Trabzon, TURKEY, 61300.

Telephone: 04623777287

Fax: 04622487344

e-mail: mustafaguler61@gmail.com

DOI: http://dx.doi.org/10.17278/ijesim.2015.01.002
} 
learning becomes. Brousseau (2002), one of the representatives of this theory, described 3 situations/settings take place teaching process: Didactic, non-didactic and adidactic. Didactical situation is a learning setting created by teacher and aimed to define students' current knowledge, change them and teach new ones by letting them know about the process. Non-didactical situation can be named as "covered learning" because of not being planned to teach something new, but ends with learning. Adidactical situation is the situation that all responsibility is given to the students. The aim of any activity in this setting is hidden and the role of teacher is to guide. There are some conditions for a setting to become adidactic.

1- The student is supposed to have the necessary preformation for solving the problem.

2- The student is supposed to construct a strategy to find the solution.

3- If the strategy is wrong, it is supposed to be realized and corrected by the student.

4- Milieu should be available for confirmation and it should give feedback.

5- The setting is supposed to be reproducible by means of the outcome which comes from the feedback.

Within the scope of this study, an adidactic learning setting was designed which aims to give opportunity to elementary mathematics teacher candidates to reflect their mathematical thinking and describing mathematical thinking process of participants was targeted.

\section{Methodology}

With this study, it's aimed to present the reflection from a designed setting targeted to find out mathematical thinking. Therefore, the study is a descriptive study by its nature. The study group of this study consists of 30 students who study in the department of Mathematics education for elementary school in a state university. In order to collect data, three researchers (one is lecturer) examined a problem statement to be able to investigate students' mathematical thinking (conjecturing, reasoning and proving, abstraction, generalization and customization). The selected problem prepared in the direction of an expert who has studies about problem solving. Here is the problem:

"When the Romans entered Jerusalem, Josephus and his 40 men hid in a cape. They decided to kill themselves just in case they were caught by the Romans. All the soldiers came together in the shape of a circle. First soldier was supposed to kill the second, third one was supposed to kill the fourth and so on. Since Josephus did not want to die, he found a place for himself in the circle and he was the only one who was not dead at the end.

a) Which place did Josephus take?

b) If the number of soldiers was "n", which place would Josephus take not to die?"

This work was carried out in one lesson (approx. $45 \mathrm{~min}$ ) hour by three researchers. The students were in the groups of two while the information was being collected. The question was not handed out ready to solve, the students were given a blank paper and pen and they were asked to write the question down and not to do scribble when they solved the problem.

\section{Findings, Discussion and Conclusion}

First of all, the students were left alone with the problem and it was expected from them to contact the researcher who was taken the Milieu position. When process is analyzed in general, the students tried to make hypothesis and they tried to use these hypothesis to test the correctness. Some of the students contacted the researcher and tried to reach the solution directly and tried to make hypothesis by trial and error. They also tried to find new conjectures instead of the ones which were proven to be wrong. On the other hand, with the discussions between different groups, they managed to propose different solutions and justify their conjectures by using mathematics. When it is lined up as the students express the most important indicators of mathematical reasoning by mathematical thinking, listen to others' mathematical thinking, propose different solutions and explain the reasons of them (Scusa, 2008); it is thought that these applications can improve the mathematical thinking. 


\section{Suggestions}

As a conclusion, it was observed that adidactic learning setting provided to reveal mathematical thinking process of students. This setting also contributed students to appropriate conjecturing and convincing as stages of mathematical thinking. In order to be able to develop students' mathematical thinking skills, teachers should be aware of the mentioned process. Thus, it is important that the teacher candidates should be informed from these activities and settings. The informal observations which were conducted by researchers also showed that the implementation were very helpful to the students for expressing their mathematical ideas. It is predicted that these kind of activities carried out in lower grades will increase the students' self-confidence and change their attitude positively to mathematics. This topic can be examined deeper in further studies.

\section{Acknowledgments}

The authors would like to thank two anonymous reviewers whose comments contributed significantly to the quality of this article. 


\section{Matematiksel Düşünme Sürecini Belirlemeye Yönelik Tasarlanmış Bir Öğrenme Ortamından Yansımalar}

\section{Derya Çelik ${ }^{1}$, Mustafa Güler², Buket Özüm Bülbüll ${ }^{3}$, Zeynep Medine Özmen ${ }^{3}$}

${ }^{1}$ Karadeniz Teknik Üniversitesi, Fatih Eğitim Fakültesi, İlköğretim Bölümü, Trabzon, TÜRKIYYE

${ }^{2}$ Karadeniz Teknik Üniversitesi, Ĕ̆itim Bilimleri Enstitüsü, Illköğretim Matematik Ĕ̆itimi, Trabzon, TÜRKiYE

${ }^{3}$ Karadeniz Teknik Üniversitesi, Eğitim Bilimleri Enstitüsü, Ortaöğretim Matematik Ĕ̆itimi, Trabzon, TüRKiYE

$\mathrm{Bu}$ çalışmada adidaktik bir öğrenme ortamında öğretmen adaylarının matematiksel düşünmelerinin resmedilmesi amaçlanmıştır. Bu amaç doğrultusunda Brousseau'nun (2002) adidaktik bir öğrenme ortamını hazırlamaya ilişkin beş aşaması dikkate alınarak bir problem durumu üzerinden ortam tasarımı yapılmıştır. Araştırma, 2012-2013 akademik döneminde bir devlet üniversitesinin İlköğretim Matematik Öğretmenliği programı ikinci sınıfında öğrenim görmekte olan 30 öğrenci ile yürütülmüştür. Çalışmanın verileri sınıf içi uygulamaya ilişkin video kamera kayıtları, araştırmaçların alan notları ve öğretmen adaylarının problem durumuna ilişkin kağıt üzerinde yaptığı açıklama ve işlemler vasıtasıyla toplanmıştır. Uygulamada öğrencilere tükenmez kalem ve kağıt dağıtılarak sergiledikleri düşünme süreçlerinin eksiksiz bir şekilde kayıt altına alınabilmesi amaçlanmıştır. Çalışma sonucunda, tasarlanan adidaktik öğrenme ortamının öğrencilerin matematiksel düşünme süreçlerinden geçmesine destek olduğu görülmüştür. Ayrıca adidaktik öğrenme ortamlarının öğrencilerin matematiksel düşünme sürecinde varsayımda bulunma ve ikna etme aşamalarını işe koşmalarına katkı sağlamıştır. Bununla birlikte araştırmacı gözlemleri, yapılan uygulama esnasında öğrencilerin aktif katılımının yüksek olduğunu göstermiştir. Elde edilen sonuçlardan hareketle hizmet öncesi öğretmen eğitiminde yapılacak bu tür etkinlerin, öğretmen adaylarının matematiksel düşünmeyi teşvik edici bir role sahip adidaktik öğrenme ortamlarını deneyimlemesi açısından faydalı olabileceği düşünülmektedir.

Anahtar Kelimeler:

adidaktik öğrenme ortamı, matematiksel düşünme, problem çözme

(c) 2015 IJESIM. Tüm hakları saklıdır.

Makale Tarihçesi:

Alındı 08.01.2015 Düzeltilmiş hali alındı 24.02.2015 Kabul edildi 11.09.2015 Çevrimiçi yayınlandı 20.10.2015

\section{Giriş}

Dünyada uygulanan öğretim programları incelendiğinde, matematik eğitiminin en önemli amaçlarından birinin matematiksel düşünme gücü gelişmiş bireyler yetiştirmek olduğu görülebilir. NCTM'in (2000) matematiksel düşünmeyi matematik eğitimi için gerekli temel bir beceri olarak tanımlamış olması bunun örneklerinden sadece biridir. Ülkemizde de, özellikle ilköğretim ve ortaöğretim programlarındaki yeniden yapılanma çalışmalarında, öğrencilerin matematiksel düşünme becerilenin geliştirilmesine yönelik belirgin vurgu olduğu görülmektedir (MEB, 2013). Ortaokul matematik dersi öğretim programında karşılaştığı problemlerin üstesinden gelebilen, matematiğe değer veren, matematiksel düşünme gücü gelişmiş, matematiği modelleme ve problem çözmede kullanabilen bireylere her zamankinden daha çok ihtiyaç duyulduğu belirtilmektedir(MEB, 2013). Matematiksel düşünme üzerine yapılan çalışmalar incelendiğinde, farklı araştırmacılar tarafından farklı tanımların yapıldığı görülmektedir. Matematiksel düşünmenin nasıl gerçekleştiğini ortaya koyması açısından matematiksel düşünmeyi bir süreç olarak ele alan tanımlamalar, eğitim-öğretim uygulamalarının geliştirilmesi için oldukça önemlidir. Bu tanımlamalardan biri de Burton'a (1984) aittir. Düşünmeyi insanın yaşamını sürdürmek ve çevresinde olup bitenleri kontrol altına almak için kullandığı bir eylem olarak gören Burton, matematiksel düşünmeyi ise bu amaca ulaşmak için toplanan bilgileri organize eden ve işleyen bir araç olarak tanımlanmaktadır (Burton, 1984). Burton'a göre (1984) matematiksel düşünme özel durumlar üzerinde çalışma, varsayımda bulunma, genelleme ve ikna etme şeklinde dört temel süreçten oluşmaktadır. Özel durumlar üzerinde çalışma belli örnekler üzerinde inceleme yapma; genelleme örüntü ve ilişkileri araştırma; varsayımda bulunma sezinlenen ilişki ve özellikleri ifade etme, ikna etme ise bir şeyin niçin doğru olduğuna ilişkin kanıtlar sunma şeklinde tanımlanabilir (Burton 1984; Stacey, 2006). Yıldırım (2000) en genel biçimde "düşünme" daha özel

Sorumlu yazarın adresi: Karadeniz Teknik Üniversitesi, Fatih Eğitim Fakültesi, Illköğretim Bölümü, Trabzon, TÜRKIYE, 61300.

Telephone: 04623777287

Fax: 04622487344

e-posta: mustafaguler61@gmail.com 
olarak matematiksel düşünmeyi bir sorun ya da problemi çözme etkinliği olarak tanımlamış ve düşünme sürecinde iki temel aşamadan bahsetmiştir. Bunlar "sorunu açıklayıcı veya giderici çözüm bulma" ve "bulunan çözümün doğruluğunu yoklama" şeklinde ifade edilebilir. Detaylı bir şekilde incelendiğinde sorunu açıklayıcı veya giderici çözüm bulma özel durumlar üzerinde çalışma, genelleme ve varsayımda bulunma süreçlerini içermektedir. Bulunan çözümün doğruluğunu yoklama ise Burton'un (1984) ikna etme sürecine karşılık geldiği söylenebilir. Breen ve O'Shea (2010) ise matematiksel düşünme üzerine literatürün sentezini yaptıkları çalışmada matematiksel düşünmeyi varsayımda bulunma, akıl yürütme ve kanıtlama, soyutlama, genelleme ve özel durumlar üzerinde çalışma şeklinde süreçleri içeren bir bütün olarak tanımlamışlardır. Farklı şekilde isimlendirmiş ve sıralanmış olsalar da, bu çalışmalar genel anlamda matematiksel düşünmenin nasıl gerçekleştiği sorusuna cevap vermesi açısından önemlidir.

Düşünme eyleminin bir sorun ya da bir problem durumu ile karşı karşıya kalındığında harekete geçtiği bilinen bir gerçektir. Matematiksel düşünme için de aynı şeyi söylemek mümkündür. Alandaki çalışmalara bakıldığında birçok araştırmacının matematiksel düşünme ve problem çözmeyi birbiri ile yakın bir şekilde ilişkilendirdiği görülmektedir (Harel \& Sowder, 2005; Polya, 1945; Schoenfeld, 1992). Schoenfeld'e göre (1992) problem çözme matematiksel düşünmenin temel bileşenlerinden biridir. Benzer şekilde Harel ve Sowder da (2005) inançlar ve kanıt şemaları ile birlikte problem çözmeyi matematiksel düşünmenin temel bileşenleri arasında göstermişlerdir. Bu durum öğrencilerin matematiksel düşünme süreçlerini harekete geçirmek için öğrenme-öğretme ortamında problem çözme uygulamalarına sıklıkla yer verilmesi anlamına gelmektedir. İyi bir problem durumu ya da bir soru öğrencilere matematiksel düşünmelerini yansıtma (Costa \& Kallick, 2000a, 2000b; Fernandez, Linares \& Valls, 2013) öğretmende de gözlem yapma (Harel \& Sowder, 2005) fırsatı vermesi açısından oldukça önemlidir. Ayrıca, bireye matematik öğretiminin en önemli amaçlarından birini -karşılaştığı problemlere çözüm bulmada matematiksel düşünmeyi etkili bir araç olarak kullanma- gerçekleştirme imkânı sağlanmış olacaktır (Stacey, 2006). Bu amaca ulaşmada en önemli görev öğretmene aittir. Öğretmenin bu görevin başarı ile üstesinden gelmesi ise benzer deneyim ve becerilere kendisinin de sahip olması anlamına gelmektedir. Bunun en etkili yollarından biri ise üniversite eğitimleri sürecinde öğretmen adayları için matematiksel düşünme fırsatı veren öğrenme ortamları tasarlamak olacaktır. Bu bağlamda bu çalışmada, öğretmen adaylarına matematiksel düşünme deneyimi sunmaya yönelik bir öğrenme ortamı tasarlama ve bu ortamdan yansımalar sunmaya odaklanılmıştır.

\section{Teorik Çerçeve}

Bir öğrenme teorisi olarak yapılandırmacılık, ulaşılacak bilgiyi bireyin oluşturmasını esas alan bir yaklaşımdır. Dewey bir süreç olarak gördüğü bu yaklaşım için 5 aşamanın önemine vurgu yapmaktadır: problemi ya da bir engeli algılama, problemi belirleme ve tanımlama, olası bir öneri sunma, önerinin geliştirilmesi ve sonraki yorumlar ile önerinin reddi ya da kabul edilmesi (Aktaran: Samaniego \& Barrera, 1999). Anlaşıldığı gibi bu yaklaşımının başlangıç aşamasını öğrencinin çözmesi gereken bir problem veya sorun oluşturmaktadır. Öğrenme sürecinde kullanılacak problemlerin niteliğini Brousseau (1997) aşağıdaki şekilde açiklamaktadır:

"Modern anlamda öğretme kavramı, öğretmenlerin öğrencileri istenilen duruma adapte etmelerini sağlayacak teşvik edici problemlerden oluşmalıdır. Bu problemler ... öğrencileri harekete geçirmeli, onları konuşturmall, düşündürmeli ve motive etmelidir... Öğgrenciler farkındadırlar ki seçilen problem onlara yeni bir bilgi parçacığı kazandıracak...(s. 30)"

Brousseau'a göre (1997) problemler öğrencileri için dikkat çekici nitelikte olmalı ve onları düşünmeye sevk etmelidir.

Yapılandırmacı yaklaşıma benzer şekilde öğretme eyleminden ziyade öğrenme eyleminin nasıl gerçekleştiğini odaklanan bir diğer yaklaşım Brousseau (2002) tarafından ortaya atılan Matematiksel Öğrenme Ortamları Kuramıdır. Bu kuram kapsamında Brousseau (2002) üç öğrenme ortamı tanımlamıştır. Bunlar:

Didaktik Ortamlar: Öğretmenin, öğrencilerinin mevcut bilgilerini ortaya çıkarmak, bu bilgileri değiştirmek veya yeni bilgiler kazandırmak amacıyla niyetini de belli ederek tasarladığı ortamdır (Brousseau, 2002). Didaktik ortamlar; öğretmenin öğrencilere bir şeyi kazandırmak amacıyla tasarlanır ve öğrenciler öğrenmeye mecbur birakılır (Bessot, 1994'den Akt: Altundă̆, 2010). 
Didaktik Olmayan Ortamlar: Brousseau'a (2002) göre didaktik olmayan ortamlar, öğretim faaliyeti içinde yer almamasına karşın bir öğrenme ile sonuçlanan doğal ortamlardır. Ortam bilgi aktarma ya da eğitim öğretim amacıyla tasarlanmış ortamlar değildir, bütün işlemler doğal süreçlerle yapılır.

Adidaktik Ortamlar: Tasarlanan öğretim ortamında tüm sorumluluğun öğrenciye ait olduğu ortamlardır. Didaktik ve didaktik olmayan ortamların bir karışımı olan adidaktik ortamlarda öğretmenin amacı belli ama gizlidir ve süreçteki rolü rehberliktir. Bu gizil amaç sonunda öğrenci farkında olmasa da öğrenme gerçekleşir (Brousseau, 2002). Adidaktik ortamlar hazırlamada bir problem durumundan yararlanılması yaygın bir yaklaşımdır (Samaniego ve Barrera, 1999). Brousseau (1997) “Öğretmen tarafından seçilen bu durum ya da problem, öğretmenin öğrencileri bağımsız ve olabildiğince verimli kılabilecek adidaktik bir ortama sokması için gerek duyduğu en önemli parçadır.(ss. 30-31)" şeklindeki açıklaması ile adidaktik ortam hazırlamada problem durumu ve niteliğinin önemini ortaya koymaktadır.

Bir ortamın adidaktik olarak adlandırılabilinmesi için bazı şartlar gerekmektedir. Bunlar: (i) öğrenci, öğrenme-öğretme ortamında problemin çözümü için belli seviyede bir önbilgiye sahip olmalı, (ii) öğrenci çözüm için bir başlangıç stratejisi ortaya koyabilmeli, (iii) kullanılan yanlış strateji öğrenci tarafından fark edilip yine öğrenci tarafından düzeltilmeli, (iv) onay için Milieu olmalı ve Milieu süreç içerisinde dönüt vermeli, (v) dönütlerden hareketle ulaşılan sonuçlara göre ortam tekrarlanabilir özellikte olmalıdır (Arslan, Baran ve Okumuş, 2011). Bunlara ek olarak Brousseau (2002) adidaktik bir öğrenme ortamının tasarlanmasında takip edilmesi gereken beş adım tanımlamıştır. Bu adımlar aşağıdaki gibi özetlenebilir (Brousseau, 2002):

1. Sorumluluk Aktarma (Devolution) Aşamasi: Tasarlanan ortamdan öğretmenin öğrenciye rolünü bildirip çekilmesi ve öğrencinin rolünü sahiplenmesi aşamasıdır.

2. Eylem (Action) Aşaması: Öğrenme ortamındaki bireyin Milieu ile etkileşim halinde olması ve ondan dönütler alması aşamasıdır. Bu dönütler süreç içinde öğrencinin kararını etkileyebilir. Dönütler yardımı ile eksik bilgiler tamamlanır ya da yanlış bilgiler düzeltilir.

3. İfade Etme (Formulation) Aşaması: Bu aşama, bireyin bir önceki aşamada elde ettiği bilgileri ifade etme ve paylaşmasını içerir. Bu aşamada da birey diğer bireylerle ve dolayısıyla Milieu ile etkileşim halindedir. Bireyler deneme yanılma veya farklı yollarla elde ettiği fikirlerini yazılı ya da sözlü olarak veya matematiksel bir dil kullanarak ifade ederler ve sahip oldukları ön bilgilerinden hareketle bir model ortaya çıkarırlar.

4. Onaylama (Validation) Aşaması: Bireylerin, bir önceki aşamada ortaya koydukları modelin neden doğru olduğunu ispat etmeleri gereken aşamadır. Modelin geçerli olması ise karşı tarafın ikna edilebilmesine bağlıdır. İkna etme sürecinde Milieu'dan dönütler alınır, bu dönütler neticesinde model revize edilir veya farklı model arayışına gidilir.

5. Kurumsallaştırma (Institionnalization) Aşaması: Milieudan alınan dönütler neticesinde onaylanan matematiksel bilgi öğretmen tarafından resmileştirildiği aşamadır. Genellenen bu bilgiye, öğretmen bir statü kazandırır.

Aşamalar dikkatli bir şekilde incelendiğinde, Brousseau'nın (2002) tanımladığı adidaktik öğrenme ortamının Burton'un (1984) ifade ettiği matematiksel düşünme süreçlerini (özel durumlar üzerinde çalışma, varsayımda bulunma, genelleme yapma ve ikna etme) ortaya çıkarma açısından önemli bir rol oynadığı söylenebilir. Sorumluluk aktarma ve eylem aşamasında öğrencilerden bir problem durumu üzerinde çalışması, çözüme önerilerini ortaya koyması, Milieu ile etkileşime girerek çözüme ilişkin eksik ve yanlış hususları düzeltmesi beklenir. Bu bağlamda bu aşamalar matematiksel düşünmede açısından özel durumlar üzerinde çalışma ve varsayımda bulunma süreçlerini teşvik edici nitelikte olabilir. İfade etme aşamasında öğrencilerin bir model ortaya koyması ve bu modeli açıklaması matematiksel düşünme açısından genelleme yapma süreci ile ilişkilendirilebilir. Onaylama ve kurumsallaştırma aşaması ise öğrencilerin Milieu'yu ve diğer öğrencileri ikna etme çabalarını ve bunların resmileştirilmesini içermektedir. Bu yönüyle bu aşamaların matematiksel düşünmenin ikna etme süreci ile yakından ilişkili olduğu söylenilebilir. Sonuç olarak, adidaktik öğrenme ortamlarının öğrencilerin matematiksel düşünme süreçlerini harekete geçirici bir yapıya sahip olduğu söylenebilir. Bu temel çıkarım çerçevesinde bu çalışmada, öğretmen adaylarının adidaktik bir öğrenme ortamında matematiksel düşünme süreçlerini incelemek amaçlanmıştır. Bu amacın adidaktik öğrenme ortamlarının matematiksel düşünmeyi geliştirme açısından nasıl bir potansiyele sahip olduğunu ortaya koymak açısından önemli olduğu düşünülmektedir. 


\section{Yöntem}

Çalışmada öğrencilerin matematiksel düşünmelerini ortaya çıkarabilmek amacıyla tasarlanmış adidaktik bir öğrenme ortamından yansımaları incelemek amaçlanmıştır. Bu sebeple yürütülen çalışma betimsel nitelikte bir çalışmadır. Bu tür araştırmalarda esas amaç, incelenen durumu etraflıca tanımlamak ve açıklamaktır (Çepni, 2009).

\section{Çalışma Grubu}

Araştırmanın çalışma grubunu 2012-2013 akademik döneminde bir devlet üniversitesinin İlköğretim Matematik Öğretmenliği programı ikinci sınıfında öğrenim görmekte olan 30 öğrenci oluşturmaktadır.

\section{Öğrenme Ortamı}

Bu çalışmada adidaktik öğrenme ortamı tasarlanarak ilköğretim matematik öğretmenliği programında okuyan öğrencilerin matematiksel düşünme matematiksel düşünme süreçlerinin resmedilmesi amaçlanmıştır. Bu bağlamda Brousseau'nun (2002) adidaktik öğrenme ortamları için tanımladığı 5 aşamadan oluşan aşamaları dikkate alınmıştır. Bu doğrultuda adidaktik öğrenme ortamı tasarlanırken bu aşamalarda dikkat edilen ilkeleri şöyle özetleyebiliriz:

Sorumluluk Aktarma Aşaması: Bu aşamada öğrenciler problemle tanıştırılır ve öğrencilere uygulama süreci ile ilgili bilgi verilir. Öğrenme ortamı düzenlenirken öğrencilerden ikişerli grup oluşturmaları ve onlara verilen kağıt kalem üzerinde aşağıdaki problemi çözmeleri istenmiştir.

“Romalılar Kudüs'e girdiğinde Josephus ve 40 asker arkadaşı bir mağarada saklanırlar. Romalılara yakalanma ihtimaline karşı teslim olmak yerine birbirlerini öldürmeye karar verirler. Tüm askerler bir halka şeklinde dizilirler. İlk asker ikinciyi, üçüncü asker dördüncüyü,.... şeklinde sırayla askerler birbirlerini öldüreceklerdir. Josephus kendisi ölmek istemediği için halkada kendine bir yer belirler. Sonuçta ölmeyen tek kişi Josephus'tur.

a) Josephus halkanın kaçıncı sırasındadır?

b) Asker sayısının n olması durumunda Josephus'un ölmemek için halkanın kaçıncı sırasında yer alması gerektiğini bulunuz?

Eylem Aşaması: Bu aşamada öğrenciler problemle baş başa bırakılmıştır. Öğrenciler problemi çözmeye çalışırken araştırmacılar rehber rolündedir. Araştırmacılar öğrencilerden gelen soru ve cevaplara doğrudan yanıt vermek yerine onlara yönlendirici sorular sormuştur. Örneğin, verilen problem durumunda öğrencilerin “Josephus'un ölmemek için hangi sırada yer alması gerektiğini bulmaları beklenmektedir. "Peki, asker sayısı 100 olsaydı en son askerin hangi sırada yer aldığını nasıl bulurduk?" soruları yöneltilerek ilk olarak onlardan varsayımda bulunmaları beklenmiştir.

İfade Etme Aşaması: Bir önceki aşamada problemi çözmeye çalışan öğrencilerin bu aşamada artık geliştirdikleri yolları yazılı olarak da ifade etmesi sağlanmıştır. Araştırmacılar bu aşamada grup içi etkileşimi oluşturarak öğrencilerin çözümlerini yazılı olarak ifade etmesi ve model oluşturması sağlanmıştır. $\mathrm{Bu}$ aşamada araştırmacılar öğrencilerden gelen cevaplara yönelik "Ortaya attığımız bu varsayımları destekleyen durumlardan bahseder misiniz?", "Varsayımımızın desteklemediği durumlar yer almakta mıdır?" gibi sorular yönelterek öğrencilerin varsayımları üzerinde akıl yürütmeleri sağlamaya çalışmıştır.

Onaylama Aşaması: Bu aşamada artık öğrenciler problemin çözümü için uygun gördükleri modelleri farklı durumlar üzerinde denemeleri ve modellerin kullanışlılığını test etmeleri sağlanmıştır. Bu süreçte gruplardan oluşturduğu modellerin kabulü için araştırmacıları ve diğer grupları ikna etmeleri istenmiştir. Araştırmacı bu aşamada "Arkadaşınızın ulaştığı cebirsel ifadeyi deneyelim bakalım. Bize bir örnek ver mesela 41 için yazdır bize." şeklindeki açıklamasıyla bir grubun geliştirdiği modele yönelik diğer grup elemanlarını ikna etmesi için teşvik etmiştir.

Kurumsallaştırma Aşaması: Bu aşamada öğrenciler tarafından geliştirilen ve sınıfça kabul gören model veya modeller araştırmacı tarafından onaylanarak genel bir şekli tahtaya yazılmaktadır. Ayrıca gruplardan bu modele nasıl ulaştığını ispat etmeleri istenmiştir.

Yukarıda belirtilen aşamalar dikkate alınarak uygulama bir ders saatinde (45 dakika) biri dersin yürütücüsü olmak üzere toplam üç araştırmacı tarafından gerçekleştirilmiştir. Araştırmacılardan birisi, 
çalışma boyunca sınıftaki uygulama sürecini öğrencilerin izni dâhilinde videoya kaydetmiş, diğer araştırmacı ise uygulama esnasında sınıfta dolaşarak alan notları tutmuştur. Dersin yürütücüsü olan araştırmacı tasarlanan bu ortamda rehber öğretmen görevini üstlenmiş, öğrencilerin planlanan matematiksel süreci yaşamalarına yardımcı olacak ve öğrencilerin verdikleri cevapları değerlendirmelerini sağlayacak şekilde yönlendirmeler yapmıştır. Bütün bu süreçte araştırmacılar Milieu görevini üstlenmiştir.

\section{Veri Toplama Araçları}

$\mathrm{Bu}$ çalışmanın veri toplama araçlarını öğrencilerin kâğıt üzerine yaptığı çözümlemeler, video kaydı ve araştırmacıların alan notları oluşturmaktadır. Uygulama sürecinde öğrencilerden verilen kâğıtlara tükenmez kalemle çözümlerini yapmaları istenmiştir. Öğrencilerin yaptığı bütün çözümleri ve karalamaları daha iyi görebilmek ve problemi çözerken yaşadıkları süreci analiz edebilmek için tükenmez kalem kullanmaları istenmiştir. Yine uygulama sürecinde sınıfta yapılan tartışmaları ve çözüm yollarına ilişkin öğrencilerin açıklamalarını ve araştırmacıların yönlendirmelerini daha iyi analiz edebilmek için video kaydı yapılmıştır. Uygulama sürecini bir araştırmacı yürütürken diğer 2 araştırmacı sınıf ortamından yansımaları daha iyi analiz edebilmek için alan notları tutmuştur.

\section{Verilerin Analizi}

Veriler analiz edilirken video kayıtlarından da faydalanılmış ve gerek grup tartışmaları gerekse araştırmacı-öğrenci dönütleri incelenmiştir. Video kayıtları izlenerek öğrencilerin belirlenen bu süreç aşamalarında ne tür cevaplar sundukları ve açıklamalarda bulundukları belirlenmiştir. Bu veriler belirlendikten sonra araştırmanın problemi doğrultusunda nitel olarak analiz edilmiştir. Bu analizler yapılırken matematiksel düşünme sürecinin özel durumlar üzerinde çalışma, varsayımda bulunma, genelleme ve ikna etme aşamalarına dikkat edilmiştir. Ayrıca öğrencilerin kağıtları incelenerek problemin çözümü için geliştirdikleri stratejiler, ulaştıkları sonuçlar, çözüme giden süreçte yaptıkları işlemler ve açıklamalar incelenerek farklı olarak rastlanan durumlar belirlenmiştir. Adidaktik öğrenme ortamından elde edilen bulgular, öğrenme ortamını oluşturan aşamalar göz önünde bulundurularak (sorumluluk aktarma, eylem, ifade etme, onaylama, kurumsallaştırma) sunulmuştur.

\section{Bulgular}

Sınıf içi gözlemler, öğrencilerin kağıt üzerindeki çözümleri ve alan notlarından elde edilen bulgular adidaktik öğrenme ortamının her bir aşaması dikkate alınarak betimsel bir yaklaşımla sunulmuştur. Ayrıca bu aşamalarda öğrencilerin matematiksel düşünme sürecinin nasıl gerçekleştĭgi ilişkin verilerde yer almaktadir.

Sorumluluk Aktarma Aşaması: Uygulamanın başında ilk olarak araştırmacı tarafından öğrencilere çalışmanın amacı ve süreçle ile ilgili açıklama yapılmıştır. Öğrencilere bir problem durumu verilerek çözüm üretmelerinin beklendiği belirtilmiştir. Daha sonra daha etkili bir problem çözme sürecinin yaşanması ve fikir alışverişlerinde bulunabilmeleri için ikişerli grup olmaları istenmiştir. Uygulama ortamının oluşturulmasından sonra problem durumu öğrencilere okunarak çalışma kâğıtlarına yazmaları istenmiştir. Araştırmacılar problem durumunu yazdırırken öğrencilere problemle ilgili yönlendirici kelimeler kullanmaktan kaçınmışlardır. Problem durumu öğrencilere yazdırıldıktan sonra uygulamanın sorumluluğu onlara verilmiş ve araştırmacılar çalışma ortamından çekilmiştir. Bu şekilde öğrenciler problem durumu ile baş başa bırakılmıştır. Çözüm öncesi ön hazırlıkları yapıldığı bu aşamada matematiksel düşünme sürecinde özel durumlar üzerinde çalışmaları sağlanmıştır.

Eylem Aşaması: Problem durumunun sunulmasıyla öğrenciler gruplar halinde çözüm için uğraşmaya başlamışlardır. Bu süreçte araştırmacılar rehber olarak görev almışlardır. Öğrencilerin problemin çözümüne yönelik varsayımlarda bulunmaları sağlanmıştır. Bu aşama öğrencilerin matematiksel düşünme süreçlerinin varsayımda bulunma aşamasına denk gelmiştir. Yine öğrenciler ile araştırmacılar problem durumu ile ilgili anlaşılamayan veya problemin çözümü için düşündükleri yollar üzerinde iletişim halindedir. Örneğin; öğrencilerden bir grup, geliştirdiği oran-orantı yöntemi ile rastgele bir ilişki arayarak yanlış sonuca ulaşmıştır. Bu durumda araştırmacı, yanlış cevabı direkt söylemek yerine, öğrencileri matematiksel düşünmeye sevk etmiştir. Bu durumda araştırmacı ile öğrenci arasında geçen konuşmalar şu şekildedir:

Ö11: 64 mü?

A: Nasıl buldun? 
Ö11: Illk başta 40 kişi yapmıştık 40 da 17 olmuştu, 41 de 19 oluyor. Arada mesela 4017 aralarında 23, 22, 21 azalıyor, o zaman 41 den 100 e 59 kişi var, 59 azalması lazım yani burada orantı yapıyor 23 de 19 sa doğru orantı ile cevabı vermeye çalışıyor.

A: Peki 3 kişi olsaydı? bakalım.

Ö11: Diyelim ki grup 3 kişi o zaman 1 kalıyor geriye. Bakalım arkadaşınızın geliştirdiği bu yöntem să̆lanıyor mu

A: Arkadaşını dedi ki 40 da 1741 de 19 arkadaşımız diyor ki ikişer ikişer artacak geliştirdiğimiz şeyle 20 veya 70 için yapsak sağlar mı?

Ö11: Hocam 20'nin altına düşünce eksiye düşüyor sağlamıyor bu yöntem.

Yukarıdaki diyalogda görüldüğü üzere Ö11 kodlu öğrenci problemin çözümüne yönelik varsayımlarda bulunmuş ve bu varsayımların doğruluğunu test etmiştir. Araştırmacı öğrenciye uygun sorular yönelterek öğrencinin varsayımının yanlış olduğunu fark etmesini sağlamıştır. Aynı zamanda öğrenci kullandığı yöntemin hangi durumlarda geçerli olduğu ile ilgili sorgulama yapmaya başlamaktadır. Bazı öğrenciler ise problemin çözümüne yönelik varsayımda bulunmak yerine doğrudan problemde yer alan 41 kişi için çizimi yaptığı ve tek tek kuralı uygulayarak kimin hayatta kalacağını bulduğu görülmüştür. Bu yol 100 kişi için çıkarım yapabilmede kullanılabilinir. Ancak bazı öğrencilerin bu işlemi 100 kişi içinde tek tek çizim yaparak uygulamaya çalıştıkları görülmüştür. Bu noktada araştırmacılar "Peki biz soruda 1000 kişi için sorsaydik o zaman nasıl yapacaktın?" şeklinde soru yöneltilerek kullandıkları bu yolun bu soru için çözüm verebileceğini ancak kişi sayısı artırıldığında yanıt vermede zorlanacaklarını hissetmeleri sağlanmıştır. Bu dönüt yardımıyla Ö8 kodlu öğrenci her ne kadar doğru cevap bulabileceğini düşünse de genel bir ifadeye ulaşması gerektiğini anlayarak "O zaman 1000 kişiyi tek tek bulamayız genel çıkarımda bulunmamız gerekir" şeklinde cevap vermiştir.

Sonuç olarak eylem aşamasında öğrenciler genellikle 100 askerin bulunması halinde en son kaçıncı kişinin kalacağı ile ilgili anlayış geliştirirken ilk olarak rastlantısal ilişkiler bulmaya çalışmışlardır. Öğrencilerden bazıları bu ilişkiyi ortaya koymak için 41 kişi üzerinde ede ettikleri sonuçtan yola çıkarak oran orantı veya örüntü yardımıyla cevap bulmaya çalıştıkları görülmüştür. Araştırmacı öğrencilerden deneme yanılmaya dayalı çözümden ziyade çözüme yönelik varsayımlarda bulunarak daha genel ve kullanışlı bir çözüm yolu elde etmelerinin çözümde gerekli olduğunu fark etmelerini sağlamıştır. Böylece araştırmacının verdiği dönütlerle yön verilen bu aşama öğrencilerin 'genel bir ifadeye nasıl ulaşabilirim' anlayışını benimsemeleriyle tamamlanmıştır.

Iffade Etme Aşaması: Bir önceki aşamada çözüm için yol geliştirme üzerine uğraşan öğrenciler daha çok karalamalar şeklinde çalışmışlardır. Bu aşamada artık öğrenciler geliştirdikleri yolları yazılı olarak da ifade ederek matematiksel düşünme sürecinde genel bir yargıya ulaşmaya çalışmışlardır. Bazı öğrenciler tüm durumları tek tek deneyerek 41 asker için çözüme ulaşmışlardır. Gruplardan birinin bu yönde yapmış olduğu çözüm aşağıdaki gibidir.

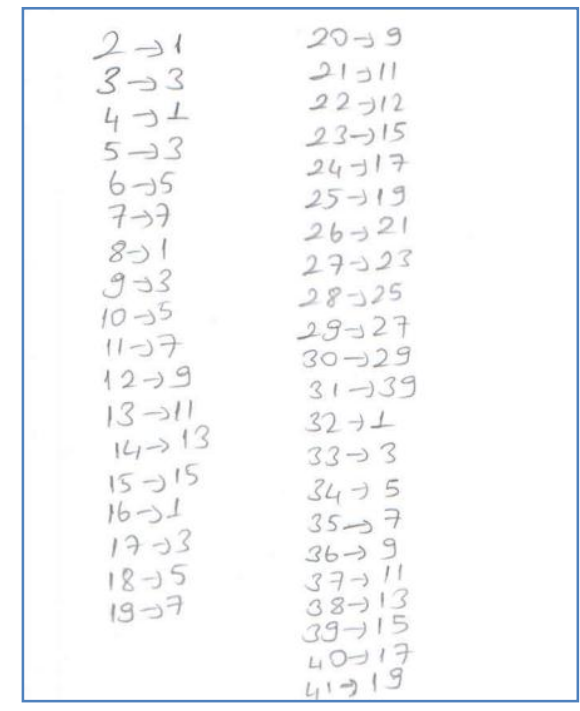

Şekil 1. Ö9 kodlu öğrencinin çözüm için kullandığı strateji 
$\mathrm{Bu}$ aşamada araştırmacı sınıfa "Bu yaptığınız işlemleri kullanarak genel cebirsel bir ifadeye nasıl ulaşabilirsiniz?" şeklinde soru yönlendirmiş, öğrencilerin yazdıkları ifadelerden genel bir çıarıma yönelmesini sağlamak istemiştir. Öğrencilerin çoğu 2'nin kuvvetlerinde kalan kişinin hep birinci sırada olduğunu fark ederek bu durumu matematiksel olarak ifade etmiştir. Katılımcılardan Ö5'in ulaştığı çıkarım Şekil 2'de verilmiştir.

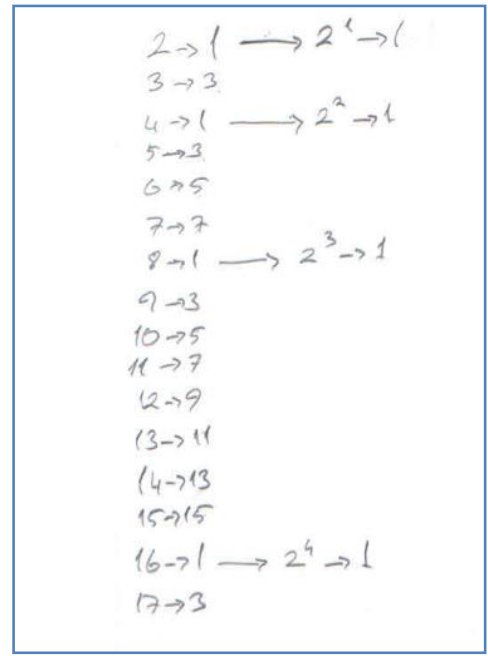

Şekil 2. Ö5 kodlu öğrencinin ifadesi

Şekil 2'de verilen çözüm incelendiğinde Ö5 kodlu öğrencinin 2'nin kuvvetlerine yönelik genel bir çıkarım yapmaya çalıştığı görülmektedir. Ancak bu çıkarımlarından yola çıkarak cebirsel genel bir ifadeye ulaşamamıştır. Bazı öğrenciler ise 2 sayısının kuvvetleri için aynı yaklaşımı kullanarak çözümlerini cebirsel ifadeye dönüştürebilmiştir. Ö7 kodlu öğrencinin cevabı bu duruma örnek teşkil etmektedir.

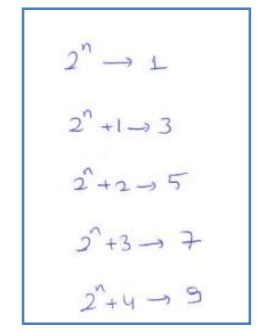

Şekil 3. Ö7 kodlu öğrencinin ulaştı̆̆ı ifade

Şekil 3'de görüldüğü üzere Ö7 kodlu öğrenci kişi sayısı içerisindeki 2'nin kuvvetleri ve kalan kişi sayısına yönelik cebirsel ifadeler kullanarak genel bir yargıya ulaşmaya çalışmıştır.

Sonuç olarak ifade etme aşamasında öğrenciler bir önceki aşamada tasarladıkları çözüm yollarını uygulayarak kağıt üzerinde ifadeler sunmuşlardır. Araştırmacının dönütleri ve onayları yardımıyla yazdıkları ifadeler için genel anlamlar oluşturmaya ve modeller ortaya koymaya çalışmışlardır.

Onaylama Aşaması: Bu aşamada artık öğrenciler problemin çözümü için uygun gördükleri modelleri farklı durumlar üzerinde denemeye ve kullanışlılığını test etmeye başlamışlardır. Modellerini test ederek tutarlılık fark etmeleri halinde modellerini açıklayarak bir nevi oluşturdukları modelin kabul edilmesi için araştırmacıları ikna etmeye çalışmışlardır. Bu aşama da matematiksel düşünmede grup arkadaşlarını, diğer grupları ve araştırmacıları ikna etme sürecini yaşamışlardır. Bu esnada araştırmacı yapılan açıklamalara yönelik sorular da yöneltmektedir. Örneğin bir grup ulaştığı ifadeyi şu şekilde açıklamaktadır:

Ö18: 2'nin kuvvetlerinde sürekli 1 e dönüyor. 2, 4, 8, 16 gibi sıra geldiğinde sürekli 1 e dönüyor.

A: 2'nin kuvvetlerinde 1 e dönüyorsa mesela 7 kişide kimin kalacă̆ını geliştirebilir miyiz?

Araştırmacının sorusu doğrultusunda öğrenciler, buldukları 2'nin kuvvetlerinde hep 1.sıradaki kişinin kaldığ 1 ifadesinden yola çıkarak başka ilişkiler bulmaya yöneltmiştir. Bu durumda öğrenciler sonraki adım olarak 1, 3; 1, 3, 5; 1, 3, 5, 7 gibi bazı ilişkilerin olduğunu fark etmişlerdir. Öğrencilerin belirli bir düzene göre tekrar eden 1,3; 1,3, 5, 7 gibi tek sayılar örüntüsü ile ilgili belirledikleri kurallar üzerine konuşulduktan sonra öğrencilerden bir tanesi daha genel yapıda geliştirdiği fikri cebirsel olarak şu şekilde ifade etmiştir: 
Ö23: Hocam mesela şöyle yapsak,

Ö23: Mesela asker sayısına $2^{k+x}$ dediğimizde, son kalan kişi için sonuç her zaman $2 x+1$ oluyor yani $k$ ya bağhl olmuyor.

A: Arkadaşınızın ulaştı̆̆ı cebirsel ifadeyi deneyelim bakalım. Bize bir örnek ver mesela 41 için yazdır bize,

Ö26: Hocam $41=2^{5+} 9$ yani burada $k=5$ ve $x=9$ oluyor [k: Toplam kişi sayısını geçmeyecek şekilde $2^{\prime}$ nin kişi sayısına en yakın kuvveti, $x$ : Toplam kişi sayısı-2k] $2^{\prime}$ nin $k 2 x+1$ ifadesinde $x$ yerine 9 yazarsak 2.9+1=1. Yani 41 kişi varsa 19. kişi kaliyor.

A: Evet doğru çıktı.

Ö24: Bunu şuradaki değerler için de deneyelim hocam.

A: Evet arkadaşımızın modelinin deneyelim bakalım farklı değerler için

Sinıf: Denediğimizde sağlıyor.

$\mathrm{Bu}$ aşama öğrencilerin elde ettikleri ilişkilerden cebirsel ifadeler oluşturmaları ve bu ifadelerin farklı durumlarda problem durumunu sağlayıp sağlamadığını kontrol etmeleriyle tamamlanmıştır. Bu şekilde öğrenci yaptığı çözüm yolu için sınıf arkadaşlarını ve araştırmacıları ikna etmeye çalışmıştır. Araştırmacı bu süreçte yapılan açıklamaları değerlendirerek tüm öğrencilerin bu matematiksel ifadenin problemin çözümü için uygun bir model oluşturup oluşturmadığına karar vermelerini istemiştir. Her ne kadar öğrenciler çözüm için bir model geliştirseler de ulaştıkları modelin her durum için neden işe yaradığına ilişkin ikna edici açıklamalarda bulunamamışlardır.

Kurumsallaştırma Aşaması: Bu aşama esasında onaylanan matematiksel bilginin öğretmen tarafından resmileştirildiği aşamadır. Ancak onaylama aşamasında öğrenciler işe yarayan bir model bulmalarına rağmen bu modelin niçin her durumda kullanışlı olduğunu ifade edememişlerdir. Bu nedenle bu aşama daha çok, Milieu ile öğrenciler arasında ortaya konulan modelin geçerliğine ilişkin tartışmalar şeklinde geçmiştir.

\section{Tartışma, Sonuç ve Öneriler}

Öğrencilerin matematiksel düşünme süreçlerini ortaya çıkarabilmek amacıyla bir adidaktik öğrenme ortamının oluşturulmasına yönelik yapılan bu çalışmada öğrenme ortamından bazı kesitler sunulmuştur. Öncelikle öğrenciler bir problemle yüz yüze bırakılmış ve bu süreçte öğrencilerin Milieu görevini üstlenen grup arkadaşları ve araştırmacılar ile etkileşime geçerek probleme bir çözüm üretmeleri beklenmiştir. Süreç genel olarak incelendiğinde öğrencilerin varsayımda bulunma ve bu varsayımı belli durumlar için deneyerek doğruluklarını test etmeye çalıştıkları görülmüştür. Ayrıca öğrencilerin bazen Milieu ile etkileşime geçerek doğrudan sonuca ulaşmaya çalıştıkları, bazen de deneme-yanılma yoluyla varsayımda bulundukları görülmüştür. Yine öğrenciler, grup arkadaşları tarafından çürütülen varsayımlar yerine farklı varsayımlar üreterek, çözüm yolu bulma gayreti içerisinde olmuştur. Diğer taraftan gruplar arasında yapılan tartışmalar, öğrencilere kendi matematiksel fikirlerini ortaya koyma fırsatı sunmasının yanında, matematiksel gerekçelere dayalı olarak varsayımlarını savunma fırsatı vermiştir. Ayrıca öğrenciler probleme yönelik varsayımları ve çözüm yolları için arkadaşlarını ikna etmeye çalışmışlardır. Matematiksel muhakemenin en önemli göstergelerini matematiksel düşünceleri ifade etme, başkalarının matematiksel düşüncelerini dinleme, farklı çözüm yolları sunma ve bunların arkasında yatan nedenleri açılama olarak ifade etme olarak sıralandığı düşünüldügünde (Scusa, 2008); bu tür uygulamaların matematiksel muhakemeyi geliştireceği düşünülmektedir.

Çalışmadan elde edilen diğer bir sonuç da öğrencilerin başlangıçta daha çok deneme yanılma veya tüm durumları yazma şeklinde stratejilere başvursalar da Milieu'nun yönlendirmeleri ve yönelttiği aşamalı sorular yardımıyla ilk olarak genel bir ifadeye ulaşmaları gerektiği düşüncesine sahip olduklarını düşünmeleridir. Dolayısıyla öğrencilerin problemi çözmeye yönelik stratejileri, onların matematiksel düşünmelerini ortaya koymuştur. Fernandez, Llinares ve Valls'in (2013), ilköğretim matematik öğretmeni adaylarının problem çözme sürecinde matematiksel düşünme farkındalıkların yönelik bir çalışmasında benzer bir durum görülmüştür. Fernandez, Llinares ve Valls'in (2013), öğretmen adaylarının farkındalıklarını seviyelendirdiği çalışmasında bazı öğretmen adaylarının problem çözümünde daha çok deneme-yanılma, tüm durumları ele alma stratejilerini kullanmaları sonucu bu çalışma ile paralellik göstermiştir. Diğer taraftan aynı çalı̧̧mada katılımcıların problem çözümünde sınırlı problem çözme stratejileri kullanmaları, sezgiye dayalı sonuca ulaşma çabaları ve bunun sonucunda yaşadıkları zorluklar, mevcut çalışmada da gözlemlenmiştir. 
Matematiksel düşünme süreçleri düşünüldüğünde, adidaktik öğrenme ortamını bu süreçlerle ilişkisinden bahsetmek faydalı olacaktır. Adidaktik öğrenme ortamı öğrencinin farkında olmadan öğrenmesini amaçladığından (Brousseau, 2002) hedeften haberdar olan yalnızca öğretmendir. Bu durumda öğretmen "Sorumluluğu aktarma" aşamasında öğrencileri problem durumuyla karşı karşıya bırakarak, öğrencilere kendi matematiksel bilgilerini oluşturmaları için fırsat sunmuştur. Öğrenciler bu durumda, grupça verilen problemi çözmeye çalışarak, görüşlerini birbirine aktarmıştır. "Eylem" aşamasında problem durumuna ilişkin deneme-yanılma, bütünü parçalara ayırma - farklı durumlar oluşturma gibi stratejiler kullandıkları görülen genel olarak bu aşamada birer hipotez kurdukları ve bu hipotezleri test ettikleri görülmüştür. Bu aşamada öğrenciler farklı problem çözme stratejilerini kullanarak doğru sonuca ulaşmaya çalışmış ve bu süreçte kararlarında deneme-yanılma yoluyla değişiklikler yapabilmiştir. Calder'in (2010) da belirttiği gibi farklı problem çözme stratejileri matematiksel düşünmenin bir parçasıdır ve bu şekilde öğrencilerin matematiksel düşünmeleri ortaya çıkar. Yine öğrencilerin matematiksel bilgilerini cebirsel olarak oluşturdukları basamak ise "İfade etme" aşaması olmuştur. Bu aşamada öğrencilerin genellemeler yapmaya çalıştıkları görülmektedir. Piaget (1970), genellemeyi üst düzey bir operasyon olarak tanımlamıştır. Ayrıca genelleme matematik eğitiminin de ana amaçları arasında yer almaktadır (Baki, 2008; Çelik, 2007; Güler, 2014). Bu sebeple sınıf ortamında yapılacak etkinliklerle öğrencilere genelleme yapabilecekleri durumları doğrudan veya örtük olarak sunmak, matematiksel bilginin inşasında önemlidir. "Onaylama" aşaması ise oluşturulan matematiksel modelin farklı durumlara uygulanmasını içerir. Çalışmada öğrencilerin, verilen durumu genelleyebilmek için farklı durumları göz önünde bulundurdukları görülmüştür. Bir bakıma öğrenciler bu aşamada farklı durumlardan hareketle genel bir sonuca ulaşma gayreti göstermişlerdir. Her ne kadar öğrenciler ulaştıkları genel formu açılama noktasında zorluk yaşasalar da, onlara tanınan bu fırsatın oluşturdukları matematiksel argümanı savunabilmeleri açısından önemli olduğu düşünülmektedir. Bu şekilde öğrenciler genel bir ifade bulma arayışında olarak bu aşamayı başarılı bir şekilde tanımlamıştır.

Özetle bu çalışmada adidaktik öğrenme ortamı aşamalarından yararlanarak öğrencilerin matematiksel düşünme süreçlerini ortaya çıkarmak amaçlanmıştır. Bu amaç doğrultusunda öğrencilerin matematiksel düşünme süreçlerinin ortaya çıkarılmasında adidaktik öğrenme ortamı aşamalarının yardımcı olduğu görülmüştür. Ayrıca adidaktik öğrenme ortamı öğrencilerin matematiksel düşünmenin varsayımda bulunma ve ikna etme aşamalarını benimsemelerine katkı sağlamıştır. Onaylama aşamasında ise öğrenciler bir önceki aşamada yaptıkları deneme yanılmalar sonucu bir model geliştirmelerine karşın bu modelin niçin doğru olduğuna yönelik geçerli argümanlar ortaya koyamamışlardır. Literatürde yer alan bazı çalışmalar da ispatın en önemli fonksiyonlarından biri olan ikna etmeye karşı (Mason, Burton \& Stacey, 1982) öğrencilerin zorluk yaşadıklarını ortaya koymuştur (Alibert \& Thomas, 1991). Ulaşılan bu sonucun tasarlanacak farklı öğrenme ortamlarında göz önünde bulundurulması ve bu aşamaya daha çok vurgu yapılması önerilmektedir. Diğer taraftan öğretim programının da amaçları arasında yer alan matematiksel düşünme becerilerinin öğrencilerde geliştirilmesi noktasında programın uygulayıcısı olan öğretmenlerin de farkındalığa sahip olmaları gerekmektedir. Bu sebeple hizmet öncesi eğitimde öğretmen adayları ile yapılacak çalışmalar ile adayların bu tür ortamlardan haberdar edilmelerinin önemli olduğu düşünülmektedir. Ayrıca araştırmacılar tarafından yapılan gözlemler sonucunda, yürütülen uygulamanın bireylerin sürece aktif katılımını sağladığı, matematiksel düşüncelerini ifade etme noktasında kendilerine fırsat sunduğu görülmüştür. Daha düşük sınıf seviyeleri ve öğretim kurumlarında yapılacak bu tür etkinliklerin öğrencilerin özgüvenlerini artıracağı ve matematiğe karşı olumlu tutumlar geliştirmede önemli bir rol oynayacağı öngörülmektedir. Bu bağlamda sonraki araştırmalarda bu konu üzerinde durulabilir.

\section{Kaynakça}

Alibert, D., \& Thomas, M. (1991). Research on mathematical proof. In D. Tall (Ed.) Advanced mathematical thinking (pp. 215-230). Kluwer: The Netherlands.

Altundağ, R. (2010). Adidaktik öğrenme ortamlarının öğrencilerin başarısı üzerine etkisi ve ortama yönelik öğrenci görüşleri. Yayımlanmamış yüksek lisans tezi, Karadeniz Teknik Üniversitesi, Eğitim Bilimleri Enstitüsü,Trabzon.

Arslan, S., Baran, D. ve Okumuş, S. (2011). Brousseau'nun matematiksel öğrenme ortamları kuramı ve adidaktik ortamın bir uygulamas1. Necatibey Faculty of Education Electronic Journal of Science \& Mathematics Education, 5(1), 204-224.

Baki, A. (2008). Kuramdan uygulamaya matematik eğitimi. (3. Baskı). Trabzon: Derya Kitapevi.

Breen, S., \& O'Shea, A. (2010) Mathematical thinking and task design, Irish Math. Soc. Bulletin, 66, 39-49. (http://www.maths.tcd.ie/pub/ims/bull66/ME6601.pdf adresinden 20.12.2013 tarihinde erişilmiştir.) 
Brousseau, G. (1997). Theory of didactical situations in mathematics. N. Balacheff, M. Cooper, R. Sutherland, \& V. Warfield (Eds. \& Trans.). Dordrecht, The Netherlands: Kluwer Academic.

Brousseau, G. (2002). Theory of Didactical Situations in Mathematics. London: Kluwer Academic Publisher.

Burton, L. (1984). Mathematical thinking: The struggle for meaning. Journal for Research in Mathematics Education. 15(1), 35-49.

Calder, N. (2010). Using stratch: An integrated problem-solving approach to mathematical thinking. Australian Primary Mathematics Classroom, 15(4), 9-14.

Costa, A.L. \& Kallick, B. (2000a). Discovering \& Exploring habits of mind. Alexandria, VA: ASCD.

Costa, A.L. \& Kallick, B. (2000b). Activating \& engaging habits of mind. Alexandria, VA: ASCD.

Çelik, D. (2007). Öğretmen adaylarının cebirsel düşünme becerilerinin analitik incelenmesi., Yayımlanmamış doktora tezi, Karadeniz Teknik Üniversitesi, Fen Bilimleri Enstitüsü, Trabzon.

Çepni, S. (2009). Araştırma ve proje çalişmalarina giriş. Trabzon: Celepler Matbaacilık.

Fernandez, C., Llinares, S., \& Valls, J. (2013). Primary school teacher's noticing of students' mathematical thinking in problem solving. The Mathematics Enthusiast, 10 (1), 440-467.

Güler, M. (2014). Öğretmen adaylarının matematik öğretme bilgilerinin incelenmesi: Cebir örneği. Yayımlanmamış yüksek lisans tezi. Karadeniz Teknik Üniversitesi, Eğitim Bilimleri Enstitüsü, Trabzon.

Harel, G. \& Sowder, L. (2005). Advanced mathematical-thinking at any age: It's nature and its development. Mathematical Thinking and Learning, 7 (1), 27-50.

Mason, J., Burton, L., \& Stacey, K. (1982). Thinking mathematically. Addison Wesley, London.

Milli Eğitim Bakanlığı [MEB], (2013). Milli Eğitim Bakanlığı Talim ve Terbiye Kurulu Başkanlığı, http://ttkb.meb.gov.tr/www/guncellenen-ogretim-programlari-ve-kurulkararlari/icerik/150 $\quad$ adresinden $28.09 .2013 \quad$ tarihinde edinilmiştir.

National Council of Teachers of Mathematics [NCTM]. (2000). Let's count in curriculum and evaluation standards for school mathematics. Reston, VA: National Council of Teachers of Mathematics.

Piaget, J. (1970). Science of education and the psychology of the child. New York: Orion Press.

Polya, G. (1945). How to solve it. A new aspect of mathematical method. Princeton University Press. Princeton, New Jersey.

Samaniego, A. H. F., \& Barrera, S. V. (1999) Brousseau in action: Didactical situation for learning how to graph functions. 4th Asian Technology Conference in Mathematics, pp. 35-41.

Schoenfeld, A. H. (1992). Learning to think mathematically: Problem solving, metacognition and sense making in mathematics. In D. A. Grouws (Ed.), Handbook of research on mathematics teaching (pp. 334-370). New York: MacMillan Publishing.

Scusa, T. (2008). Five Processes of Mathematical Thinking. Projects for MA Degree. Paper 38. (http://digitalcommons.unl.edu/mathmidsummative/38 adresinden 11.09.2013 tarihinde erişilmiştir.)

Stacey, K. (2006). What is mathematical thinking and why is it important? Progress report, Collaborative Studies on Innovations for Teaching and Learning Mathematics in Different Cultures (II)-Lesson Study focusing on Mathematical Thinking. CRICED: University of Tsukuba.

Yıldırım, C. (2000). Matematiksel düşünme (3. baskı). İstanbul: Remzi Kitabevi. 